\title{
EVALUATION OF COMPREHENSIVE DENTAL TREATMENT UNDER GENERAL ANESTHESIA IN HEALTHY AND DISABLED CHILDREN (RETROSPECTIVE STUDY)
}

\author{
Moussa Shady A.* and Nasr Rania A.**
}

\begin{abstract}
Background: Pediatric dentists provide oral care and solve dental problems for infants, children, and adolescents using non-pharmacological behavior modification techniques. However, some children who have extensive dental problems cannot cooperate due to a lack of psychological or emotional maturity and/or mental, physical or medical disabilities, and their dental treatment needs to be completed with pharmacological behavior management, such as nitrous oxide/oxygen sedation or general anesthesia. Differences in dental treatment under general anesthesia (G.A) in healthy and disabled children are rarely reported.
\end{abstract}

Purpose: This retrospective study evaluated the treatment modalities performed under G.A. in pediatric dental patients and compared the different treatment patterns performed in healthy children and children with special health care needs.

Subjects \& Methods: The data from the patients' personal profiles were retrospectively reviewed, including general history, dental history, reasons for G.A and treatment modalities. Patients less than 15 years old treated under G.A. at Pediatric Dentistry Unit of King Saud Hospital from September, 2008 to December, 2013 were divided into two groups. Patients with special health care needs who had at least one type of mental or physical or psychological disabilities or medically compromised, possibly unable to tolerate treatment under local anesthesia alone or together with inhalation sedation were assigned to $($ Group $\beta)$ and the other healthy patients with substantial dental needs who were extremely uncooperative or uncommunicative with no expectation that their behavior would soon improve were assigned to (Group $\pi$ ). Comprehensive dental treatment under G.A had been provided for the patients. The treatment modalities of simple filling restoration, crowns, pulp therapy, fissure sealant and teeth extraction were statistically analyzed and compared in the two groups by using t-test.

Results: A total of 756 patients were treated under G.A, 641 patients were included in (Group $\pi)$ and 115 patients were assigned to $($ Group $\boldsymbol{\beta})$. There were insignificant differences in ages, sex and total number of treated teeth in both groups, $\mathrm{p}>0.001$. $59 \%$ of group $\pi$ and $40.9 \%$ of group $\beta$

\footnotetext{
* Lecturer and Consultant Pediatric Dentistry and Dental Public Health, Zagazig University, Egypt.

** Assistant Professor Pediatric Dentistry and Dental Public Health Department, Faculty of Dentistry, Cairo University, Egypt.
} 
(less than 6-years) had significant differences in treatment modalities, with $\mathrm{P}<0.05$. The mean of extracted teeth was significantly greater in group $\beta$ and there was a significant increase of sealant procedures in group $\pi$, there also were significant increases in using crowns and pulp-therapies in group $\beta$. However, $41 \%$ of group $\pi$ and $59.1 \%$ of group $B$ were (older than 6years) showed a significant increase in teeth-extraction in group $\beta$ but there were more crowns and pulp-therapies in group $\pi$ but there were insignificant differences in restoration and sealant procedures between groups, $\mathrm{P}>0.05$.

Conclusions: For very young children or those with special health care needs, dental treatment performed under general anesthesia is beneficial and efficient. The findings of this study suggest that underlying medical or mental conditions may influence the dental condition and treatment modality provided.

KEYWORDS: Comprehensive Dental Care, General Anesthesia, Special Needs Children, Dental Care

\section{INTRODUCTION}

According to a recent review, currently there are no certain accepted protocols for the provision of dental treatment under general anesthesia (dental general anesthesia, DGA) to patients with special health care needs ${ }^{(1)}$. However, DGA presents the most commonly used technique for uncooperative patients in need for (extensive) dental rehabilitation (2). Dentistry for individuals with special needs (also referred to as persons with "disablement," "impairment," “disability," and "handicap,") as defined by the WHO (3) encompasses the management of patients with intellectual, physical, psychiatric, and complex medical problems ${ }^{(4)}$.

Such patients are prone to insufficient oral health care and subsequent caries or periodontal diseases (5-9) and frequently display anxiety and noncooperation, rendering routine dental examination or treatment difficult or may be impossible.

Several studies have assessed a high caries prevalence in children and adults with special needs worldwide with decayed-missing-filled teeth (dmft) and (DMFT) high scores respectively depending on the age, their cooperating ability with dental treatment and the type of associated disability. In patients who are unamenable to conventional dental procedures, DGA provides a chance for optimized treatment conditions.
The majority of children can be adequately treated with non-pharmacologic behavior management techniques such as Tell-Show-Do technique. However, some children who have extensive dental problems and cannot cooperate due to a lack of psychological or emotional maturity and/or mental, physical or medical disabilities, their dental treatment has to be completed with pharmacological behavior management, such as nitrous oxide/oxygen sedation or general anesthesia. ${ }^{(10-13)}$

Behavioral management has a crucial role in facilitating the provision of high quality dental treatment for children and ensuring safe and painless environment ${ }^{(1)}$. While some children receive treatment in a dental chair, for more severe cases, SHCN patients or child behavioral problems, general anesthesia (G.A.) may be unavoidable choice $^{(14)}$.

The American Academy of Pediatric Dentistry defines SHCN as "any physical, developmental, mental, sensory, behavioral, cognitive, or emotional impairment or limiting condition that requires medical management, health care intervention, and/ or use of specialized services or programs. The condition may be developmental or acquired and may cause limitations in performing daily selfmaintenance activities or substantial limitations in a major life activity" ${ }^{(15)}$. Children with special health care needs (SHCN) are highly susceptible 
to have poor oral hygiene and poorer periodontal status with untreated carious teeth, ${ }^{(5,16,17)}$ since most of them have limited motor and sensory coordination skills and are consequently unable to care for themselves and must rely on their parents or caregivers for general care ${ }^{(18)}$. In addition, these patients frequently show high anxiety levels, a low level of cooperation, and mood swings, which form a barrier to dental treatment in the conventional local setting ${ }^{(1)}$.

Studies on several populations have shown high unmet dental needs among children with SHCN (18-21). Therefore, DGA presents a very important option for dentists to perform comprehensive dental care of children with SHCN because of the above mentioned reasons and to overcome the potential risks, excessive stress, and inability to offer highquality dental treatment in the dental chair ${ }^{(22)}$.

General Anesthesia provided dental treatment allows a total oral rehabilitation in a single course, including a full mouth prophylaxis treatment, conservative dental restoration, pulp therapy, tooth extraction, full coverage reconstruction, and preventive resin restoration.

There are studies compared the dental treatments performed under G.A. between children with SHCN and healthy children ${ }^{(23-28)}$. The majority of these studies reported higher frequency of extractions in children with SHCN when compared to healthy children ${ }^{(24-28)}$. Some of these studies reported significantly less frequency of pulp therapy and stainless steel crowns among children with SHCN $(23,26,27)$, while others reported significantly more restorative treatment among this special group of children ${ }^{(24,25)}$.

Little scientific research is made on the differences in dental treatment performed under G.A. between healthy children and children with $\mathrm{SHCN}$ in the Arab region in general.

Therefore, the purposes of this retrospective study were first, to evaluate the characteristics and treatment modalities under general anesthesia in pediatric dental patients in King Saudi Hospital from 2008 to 2013, and second, to compare the different treatment patterns between healthy children and children with special health care needs.

\section{MATERIALS AND METHODS}

According to World Medical Association Declaration of Helsinki, study population and ethical local institutional approval for this retrospective study is obtained. All parents or legal guardians received adequate information and written consent for types of treatment procedures and for collection patient's recorded data. ${ }^{(29)}$

In this study, complete dental records of all pediatric patients aging from ${ }^{(1-15)}$ years who received full mouth rehabilitation under G.A. in the Pediatric Dentistry Unit of King Saudi Hospital from September, 2008 to December, 2013 were reviewed. These patients consisted of a certain percentage of healthy children having substantial dental needs but extremely uncooperative or uncommunicative with no expectation that their behavior would soon improve. Other patients with certain physical / mental or psychological disabilities or medically compromised and were possibly unable to tolerate treatment under local anesthesia alone or together with inhalation sedation.

The patients included in the current study were divided into two groups; those with SHCN who had at least one type of mental or physical or psychological disability or medically compromised, were assigned to the SHCN Group called (Group $\boldsymbol{\beta})$ and those without any of such disabilities but with difficulty in cooperating capabilities, were included in the healthy Group called (Group $\boldsymbol{\pi}$ ). Further subgrouping was done to the patients according to their age group ( $<6$ years or $\geq 6$ years).

- (Group B): Patients with special health care needs who had at least one type of mental or physical disability, possibly unable to tolerate 
treatment under local anesthesia alone or together with inhalation sedation.

- $($ Group $\pi)$ : The other healthy patients with substantial dental needs who were extremely uncooperative or uncommunicative with no expectation that their behavior would soon improve

\section{-Data collection:}

The data from the patients' personal profiles were retrospectively reviewed, including general history, dental history, reasons for G.A. and treatment modalities performed during the procedure.

The data collected from the patients treatment records included the total number of restored primary teeth, restored permanent teeth (including those which were treated with preventive resin restoration), the total number of crowns (including stainless steel crowns (SSCs), composite strip crowns, zirconia, and pre-veneered SSCs), the total number of fissure sealed primary and permanent teeth, the total number of pulpally treated primary and permanent teeth (including indirect pulp treatment, direct pulp treatment, pulpotomy, pulpectomy, and root canal treatment procedures), the total number of extracted primary teeth, and extracted permanent teeth (including supernumerary teeth extraction).

All patients included in this study had received appropriate dental and anesthetic pre-operative assessments. Dental assessment included the past and present dental history, medical history, intraoral / extra oral clinical examinations, oral radiographs and appropriate hematological tests. Comprehensive full mouth treatment under G.A. had been provided for the patients included in the study. All dental procedures were carried out under G.A. with nasoendotracheal intubation by a specialized senior pediatric dentist and in case of uneventful procedure, patients were discharged 2 hours after recovery.

\section{- Statistical Analyses:}

Data were recorded and analyzed using threeway ANOVA and Bonferroni post hoc test with $p<0.05$ indicating significance using the SPSS computer software (SPSS Version 20, Chicago, IL, USA).

\section{RESULTS}

A total number of 756 patients were treated under General Anesthesia and included in the study. 641 patients were included in (Group $\pi$ ) and 115 patients were assigned to (Group $\beta)$. (Table I \& Table II) (Figure 1a, 1b).

TABLE (I): Classification of study groups according to the age.

\begin{tabular}{|l|c|c|c|c|}
\hline \multicolumn{1}{|c|}{ Variable } & Group $\pi$ & $\%$ & Group $\beta$ & $\%$ \\
\hline Total Under 6 years & 378 & $58.97 \%$ & 46 & $40 \%$ \\
\hline Total 6-15 years & 263 & $41.03 \%$ & 69 & $60 \%$ \\
\hline Total & 641 & $100 \%$ & 115 & $100 \%$ \\
\hline
\end{tabular}

TABLE (II): Number of children of the study groups depending on sex and age.

\begin{tabular}{|l|c|c|}
\hline \multicolumn{1}{|c|}{ Variable } & Group $\pi$ & Group $\beta$ \\
\hline Males under 6 years & 146 & 24 \\
\hline Females under 6 years & 232 & 22 \\
\hline Males between 6-15 years & 124 & 38 \\
\hline Females between 6-15 years & 139 & 31 \\
\hline
\end{tabular}

TABLE (III): The Major Underlying Medical Problems in Group ß

\begin{tabular}{|c|c|c|}
\hline Variable in $\beta$ group & Number of cases & $\%$ \\
\hline Diabetic & 15 & $13 \%$ \\
\hline Renal failure & 4 & $3.5 \%$ \\
\hline Cardiac & 7 & $6 \%$ \\
\hline Mental retarded & 44 & $38.3 \%$ \\
\hline Autism & 9 & $7.8 \%$ \\
\hline Cerebral palsy & 23 & $20 \%$ \\
\hline Growth delayed & 3 & $2.6 \%$ \\
\hline Epilepsy & 10 & $8.7 \%$ \\
\hline
\end{tabular}


There were insignificant differences in ages, sex and total number of treated teeth in both groups (Group B and Group $\pi$ ), p $>0.001$.

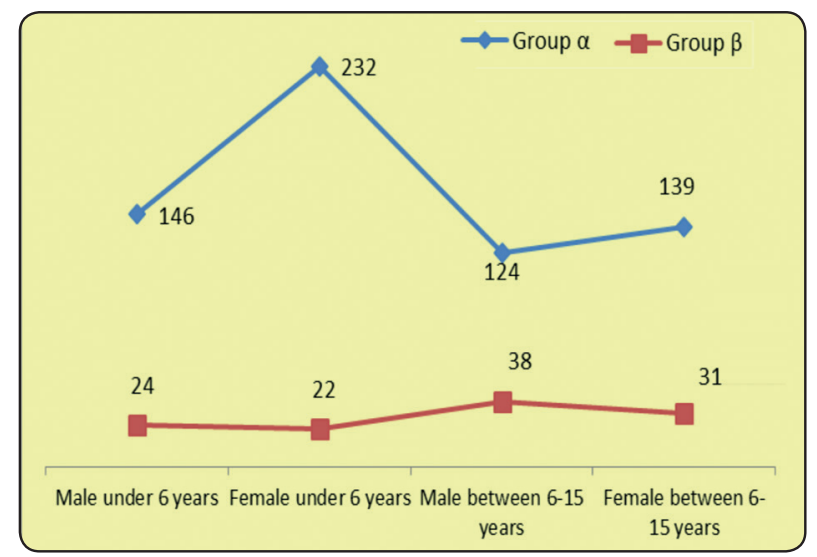

Fig. (1a): Classification of (Group $\pi$ ) and (Group $ß)$ according to the Age

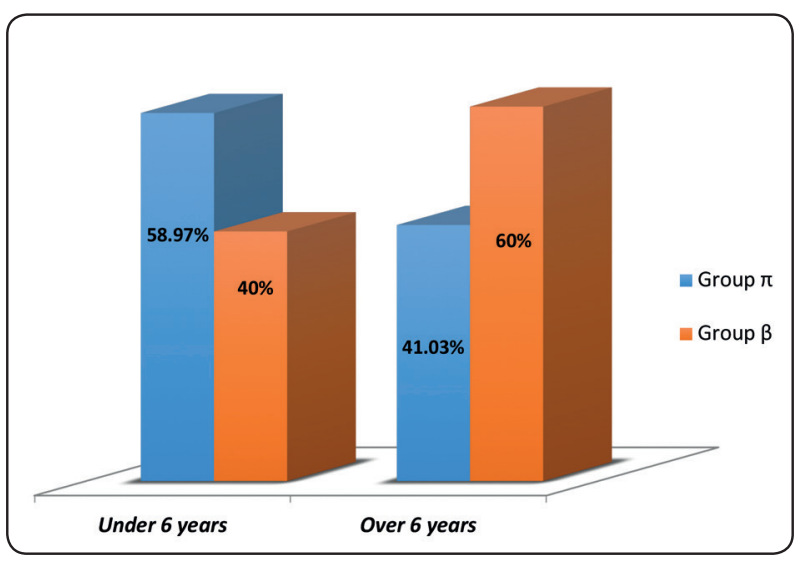

Fig. (1b): Classification of (Group $\pi$ ) and (Group $\beta$ ) according to the Age.
$59 \%$ of Group $\boldsymbol{\pi}$ and $40.9 \%$ of Group B (less than 6-years) had significant differences in treatment modalities, with $\mathrm{P}<0.05$. The mean of extracted teeth was significantly greater in Group B and there was a significant increase of sealant procedures in Group $\boldsymbol{\pi}$, there also were significant increases in using crowns and pulp-therapies in Group B. shown in (Table IV, Figure 3).

However, $41 \%$ of Group $\boldsymbol{\pi}$ and $59.1 \%$ of Group B were (equal or older than 6years) showed a significant increase in teeth-extraction in Group B but there were more crowns and pulp-therapies in Group $\pi$ but there were insignificant differences in restoration and sealant procedures between groups, $\mathrm{P}>0.05$. Shown in (Table V, Figure 4).

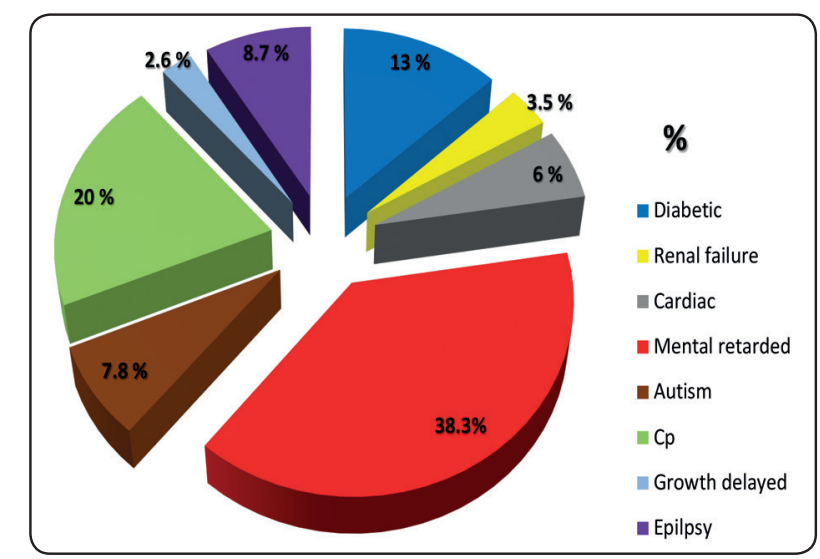

Fig. (2): The Major Underlying Medical Problems in Group $§$

TABLE (IV): The dental treatment modalities performed in healthy children and children with special health care needs according to age group $(<6$ years $)$

\begin{tabular}{|l|c|c|c|}
\hline \multicolumn{1}{|c|}{ Treatments In Patients <6 Years } & Group $\pi$ & Group $\beta$ & $P$ \\
\hline Extraction procedure & $(4.656) \pm(2.656)$ & $(5.804) \pm(1.784)$ & 0.0028 \\
\hline Crown capping & $(3.486) \pm(1.857)$ & $(4.50) \pm(1.345)$ & 0.0003 \\
\hline Pulp Therapy & $(4.423) \pm(1.684)$ & $(5.217) \pm(1.052)$ & 0.0009 \\
\hline Restoration by simple filling & $(3.523) \pm(1.731)$ & $(4.13) \pm(1.746)$ & 0.0127 \\
\hline Pit and fissure sealant application & $(1.978) \pm(1.352)$ & $(1.304) \pm(1.008)$ & 0.0005 \\
\hline
\end{tabular}

Data is given as mean $\pm S D$ (standard deviation) 


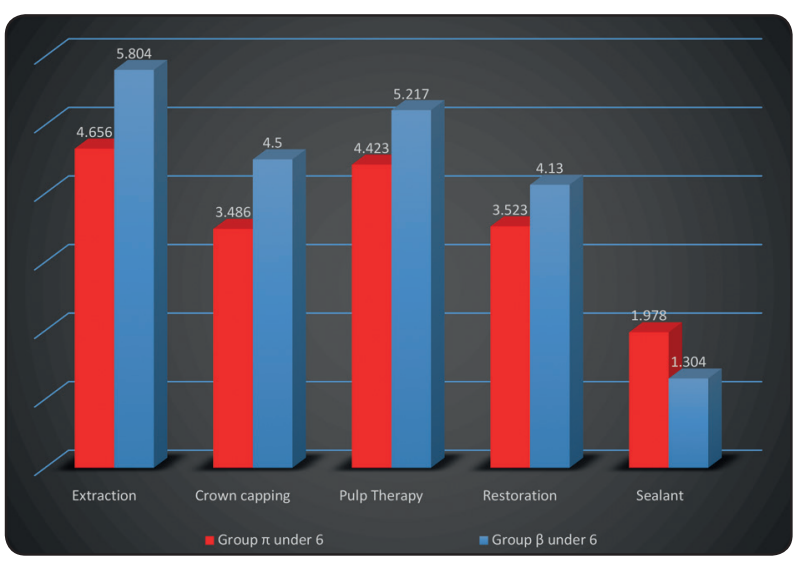

Fig. (3): Comparison between the Mean of treated teeth through different treatment modalities among Group $\pi$ and Group $\beta$ for the younger patients (Under 6 years old).

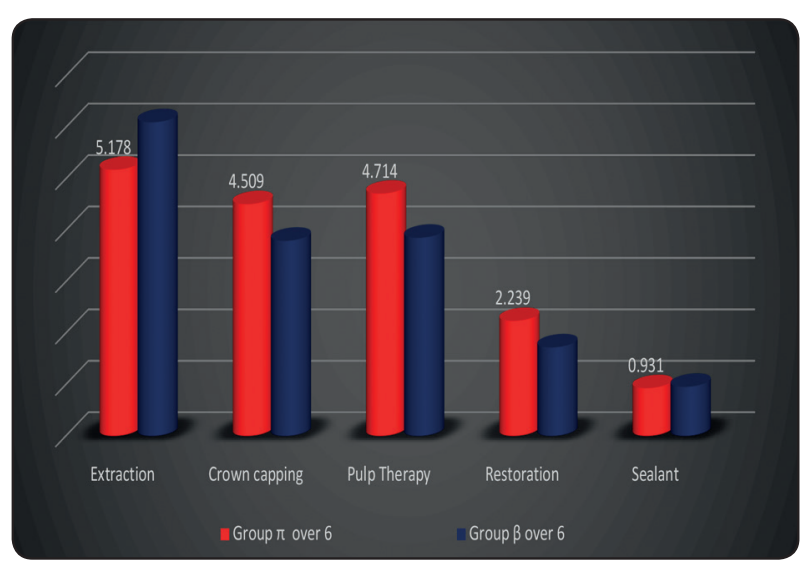

Fig. (4): Comparison between the Mean of treated teeth through different treatment modalities among Group $\pi$ and Group $\beta$ for the older patients (Over 6 years old).

TABLE (V): The dental treatment modalities performed in healthy children and children with special health care needs according to age group ( $\geq 6$ years)

\begin{tabular}{|c|c|c|c|}
\hline Treatments In Patients $\geq 6$ Years & Group $\pi$ & Group $\beta$ & $P$ \\
\hline Extraction procedure & $(5.178) \pm(2.333)$ & $(6.101) \pm(1.963)$ & 0.00138 \\
\hline Crown capping & $(4.509) \pm(2.1)$ & $(3.797) \pm(2.434)$ & 0.0079 \\
\hline Pulp Therapy & $(4.714) \pm(3.489)$ & $(3.855) \pm(2.259)$ & 0.0048 \\
\hline Restoration by simple filling & $(2.239) \pm(1.978)$ & $(1.724) \pm(1.446)$ & 0.191 \\
\hline Pit and fissure sealant application & $(0.931) \pm(0.778)$ & $(0.956) \pm(0.758)$ & 0.325 \\
\hline
\end{tabular}

Data is given as mean $\pm S D$ (standard deviation)

\section{DISCUSSION}

High quality service dental treatment for special health care needs patients is commonly performed under G.A. in hospital-based setting as it is the ideal location to ensure safety of these patients ${ }^{(30)}$. In this study, children with SHCN constituted about one fifth of children treated under GA. Close percentage (23\%) was reported in another study in Saudi Arabia ${ }^{(31)}$. In addition, more children with SHCN were from the older age group category ( $>6$ years) at the time of treatment when compared to healthy children (60\% vs $41.03 \%$ for healthy children); a finding which was also reported in previous studies ${ }^{(27,31)}$. The two major underlying problems in children with SHCN who were treated under GA in this study were mental retardation and cerebral palsy. These two conditions were also reported by De Nova García et al. ${ }^{(32)}$ as being the most common diagnosis for SHCN children treated under GA.

In this study, primary teeth extractions followed by primary teeth pulp therapies then crown capping and finally pit and fissure sealant application was the sequence of most frequently performed procedures under GA for children with SHCN. Similar finding was reported by Al-Malik and Al-Sarheed ${ }^{(31)}$ and Ibricevic et al. ${ }^{(23)}$.

However, when the treatment modalities between healthy children and children with SHCN were compared, there were insignificant differences in ages, sex and total number of treated teeth in both Groups, $p>0.001$. 59\% of Group $\pi$ and $40.9 \%$ of Group B (less than 6-years) had significant 
differences in treatment modalities, with $\mathrm{P}<0.05$, except for the restorative treatment by simple filling. The mean of extracted teeth was significantly greater in Group B and there was a significant increase of sealant procedures in Group $\boldsymbol{\pi}$, there also were significant increases in pulp therapies and using crowns in Group B. similar findings were reported in previous studies ${ }^{(26-28)}$.

On the other hand, the older age groups, $41.03 \%$ of Group $\boldsymbol{\pi}$ and $60 \%$ of Group B (6-years and older) had significant differences in treatment modalities, with $\mathrm{P}<0.05$, except for the restorative treatment by simple filling and pit \& fissure sealant. The mean of extracted teeth was significantly greater in Group B and there was a significant increase of pulp therapy procedures and crown capping in Group $\boldsymbol{\pi}$. There was also insignificant increase in simple restorative treatment in Group $\pi$. However the mean of pit and fissure sealant procedures was insignificantly similar in the both groups of the older age.

This may indicate that at the time GA was performed, children with SHCN presented with higher caries activity in both dentitions (primary and permanent) coupled with more un-restorable primary teeth when compared to healthy children, consequently the decision was in favor of extraction for the un-restorable teeth in these patients and restoration of teeth with limited caries activity. The extraction was the most common chosen treatment for badly decayed primary and permanent teeth with potential or actual damage to the pulp especially in children with SHCN (Group B).

The decision seemed to favor extraction over some form of pulp therapy and this interpretation needs to be taken with caution, as no assessment was made in the present study for the decayed missing and filled primary teeth (dmf-t) and permanent teeth (DMF-T) scores in both groups studied which can be considered a limitation. Nevertheless, Brown (33) reported higher mean dmft score for 5 year-old medically compromised patients in Riyadh, Saudi
Arabia when compared to healthy children (9.91 vs. 6.25 ), while that was not a population-based study as well, it is very likely that this pattern reflects the fact that of the community in many overseas studies, which also found that medically compromised children had a high mean dmft even when compared to healthy children ${ }^{(24,34,35)}$.

Another explanation of the present findings would be that the treatment decision got influenced by the health status of the child. This observation was also suggested in previous studies $(23,27,28,36)$. Dentists may prefer a less complex and more radical dental procedure under GA for a SHCN child to avoid complications or the necessity for retreatment than a healthy child ${ }^{(27,36)}$. This makes sense even for healthy children in cases of frank, invasive periapical pathology. In that case extraction rather than heroic pulpal modalities and esthetic crowns should be done as definitive treatment, as intervention intended to minimize further complications or follow-ups should be the approach to take when working under GA with high risk patients, just as full coverage is the more preferable rather than "fillings" for grossly decayed teeth ${ }^{(37)}$.

In this study, regardless of the medical health of the child (healthy or SHCN), younger children ( $<6$ years) received more crowns, pulp therapy treated teeth, and primary teeth restorations while they received less fissure sealed teeth, extracted teeth less than older children ( $\geq 6$ years) with statistically significant differences. This finding is in part in agreement with Chen et al. ${ }^{(38)}$ who found less mean number of crowns and pulpotomized teeth in children $\geq 6$ years and higher mean number of extracted teeth than younger children $<6$ years. This would be likely due to the fact that most primary teeth among this age group (mixed dentition) were at a late stage and would be exfoliated in a few years. In such circumstances, the need for pulp therapy and crowns may have been converted to tooth extraction. 
In summary, the present findings from this study reveal an overall difference in the treatment approach under G.A. between healthy children and children with SHCN. The use of more radical treatment approaches like extraction in children with SHCN and the lessened preference toward pulp therapy coupled with greater need for permanent teeth restorations when compared to healthy children were observed. Therefore, more implemented efforts on oral health education and preventive strategies for children with SHCN is required.

\section{CONCLUSIONS}

For very young children or those with special health care needs, dental treatment performed under general anesthesia is beneficial and efficient. The current study findings suggest that underlying medical or mental conditions may influence the dental condition and treatment modality provided. For disabled children, the dentist may choose a dental procedure which is less complex or has a lower risk of complications, such as extraction. It is extremely important to educate the parents/ caregivers of children with SHCN on the importance of establishing early dental home.

\section{RECOMMENDATION}

Dental health education of parents/caregivers is critical for ensuring appropriate and regular supervision of daily oral hygiene as majority of children with SHCN have limited ability to perform daily oral hygiene measures consequently parents/caregivers should provide the appropriate oral care when the patient is unable to do so adequately. Caregivers' lack of awareness and knowledge can also limit a SHCN child from receiving proper preventive dental care especially when the relationship between oral health and general health is not well understood. At the same time, the dental home provides an opportunity to implement individualized preventive oral health care practices and reduces the patient's risk of preventable dental/ oral disease.

\section{ACKNOWLEDGEMENTS}

The authors are thankful to all children, participants and their parents or guardians for their valuable participation in this study. This study was supported clinically by all staff members of Pediatric Dentistry Unit, King Saud Hospital (Unaizah, KSA), really appreciating their continuous encouragement, cooperation and support.

\section{Conflict of Interest}

The authors declare that they do not have any financial interest, arrangement or affiliation with anyone in relation to this research that could be perceived as a real or apparent conflict of interest in the context of the subject of this study. This study was supported by self-fund from authors.

\section{REFERENCES}

1. Mallineni SK, Yiu CK (2016) Dental treatment under general anesthesia for special-needs patients: analysis of the literature. J Investig Clin Dent 7:325-331. https://doi. org/10.1111/jicd.12174

2. Vargas-Román MP, Rodríguez-Bermudo S, Machuca-Portillo G (2003) Dental treatment under general anesthesia: a useful procedure in the third millennium? (1). Med Oral $8: 129-135$

3. WHO (1980) International classification of impairments, disabilities, and handicaps. https://whqlibdoc.who.int/ publications/1980/9241541261_eng.pdf. Accessed 3 Feb 2019.

4. Royal Australasian College of Dental Surgeons (2017) Specialist Dental Practice 2014. https://www.racds.org/ RACDSNEW_Content/Education/Specialist_Dental_ Practice.aspx. Accessed 4 April 2017.

5. Nunn JH, Davidson G, Gordon PH, Storrs J (1995) A retrospective review of a service to provide comprehensive dental care under general anesthesia. Spec Care Dentist 15:97-101

6. Pregliasco F, Ottolina P,Mensi C, Carmagnola D, Giussani F, Abati S, Strohmenger L (2001) Oral health profile in an institutionalized population of Italian adults with mental retardation. Spec Care Dentist 21:227-231. 
7. Schulte AG, Freyer K, Bissar A (2013) Caries experience and treatment need in adults with intellectual disabilities in two German regions. Community Dent Health 30:39-44.

8. Da Silva SN, Gimenez T, Souza RC, Mello-Moura ACV, Raggio DP, Morimoto S, Lara JS, Soares GC, Tedesco TK (2017) Oral health status of children and young adults with autism spectrum disorders: systematic review and meta-analysis. Int J Paediatr Dent 27:388-398. https://doi. org/10.1111/ipd.12274

9. Morgan JP, Minihan PM, Stark PC, Finkelman MD, Yantsides KE, Park A, Nobles CJ, TaoW, Must A (2012) The oral health status of 4,732 adults with intellectual and developmental disabilities. J Am Dent Assoc 143:838846.

10. American Academy of Pediatric Dentistry Clinical Affairs Committee. American Academy of Pediatric Dentistry Council on Clinical Affairs-Guideline on behavior guidance for the pediatric dental patient. Pediatr Dent 2005-2006; 27:92-100.

11. Roeters J, Burgersdijk R. The need for general anesthesia for the dental treatment of mentally handicapped patients: a follow-up study. ASDC J Dent Child 1985; 52:344-6.

12. Enger DJ, Mourino AP. A survey of 200 pediatric dental general anesthesia cases. ASDC J Dent Child 1985; 52:3641.

13. Vermeulen M, Vinckier F, Vandenbroucke J. Dental general anesthesia: clinical characteristics of 933 patients. ASDC J Dent Child 1991; 58:27-30.

14. Guideline on Behavior Guidance for the Pediatric Dental Patient. Pediatr Dent. 2016; 38:185-98.

15. Guideline on management of dental patients with special health care needs. Pediatr Dent. 2016; 38:171-6.

16. Martens L, Marks L, Goffin G, Gizani S, Vinckier F, Declerck D. Oral hygiene in 12-year-old disabled children in Flanders, Belgium, related to manual dexterity. Community Dent Oral Epidemiol. 2000; 28:73-80.

17. Vignehsa H, Soh G, Lo GL, Chellappah NK. Dental health of disabled children in Singapore. Aust Dent J. 1991; 36:151-6.

18. Chen CY, Chen YW, Tsai TP, Shih WY. Oral health status of children with special health care needs receiving dental treatment under general anesthesia at the dental clinic of Taipei Veterans General Hospital in Taiwan. J Chin Med Assoc. 2014; 77:198-202.
19. Nelson LP, Getzin A, Graham D, Zhou J, Wagle EM, McQuiston J, et al. Unmet dental needs and barriers to care for children with significant special health care needs. Pediatr Dent. 2011; 33:29-36.

20. Lewis CW. Dental care and children with special health care needs: a population-based perspective. Acad Pediatr. 2009; 9:420-6.

21. Jamieson LM, Koopu PI. Child use of dental services and receipt of dental care in New Zealand. J Paediatr Child Health. 2007; 43:732-9.

22. Blayney MR, Malius AF, Cooper GM. Cardiac arrhythmias in children during outpatient general anesthesia for dentistry: a prospective randomized trial. Lancet 1999; 354:1864-6.

23. Ibricevic H, Al-Jame Q, Honkala S. Pediatric dental procedures under general anesthesia at the Amiri Hospital in Kuwait. J Clin Pediatr Dent. 2001; 25:337-42.

24. Sari ME, Ozmen B, Koyuturk AE, Tokay U. A retrospective comparison of dental treatment under general anesthesia on children with and without mental disabilities. Niger J Clin Pract. 2014; 17:361-5.

25. Ahuja R, Jyoti B, Shewale V, Shetty S, Subudhi SK, Kaur M. Comparative Evaluation of Pediatric Patients with Mental Retardation undergoing Dental Treatment under General Anesthesia: A Retrospective Analysis. J Contemp Dent Pract. 2016; 17:675-8.

26. Tsai CL, Tsai YL, Lin YT, Lin YT. A retrospective study of dental treatment under general anesthesia of children with or without a chronic illness and/or a disability. Chang Gung Med J. 2006; 29:412-8.

27. Lee PY, Chou MY, Chen YL, Chen LP, Wang CJ, Huang WH. Comprehensive dental treatment under general anesthesia in healthy and disabled children. Chang Gung Med J. 2009; 32:636-42.

28. Baygin O, Tuzuner T, Kusgoz A, Yahyaoglu G, Yilmaz N, Aksoy S. Effects of medical and mental status on treatment modalities in patients treated under general anaesthesia at the KTU Faculty of Dentistry in Trabzon, Turkey: A comparative retrospective study. J Pak Med Assoc. 2017; 67:305-7.

29. World Medical Association Declaration of Helsinki, Ethical principles for medical research, involving human subjects. J Amer Medi Asso. 2013.

30. Park MS, Sigal MJ. The role of hospital based dentistry in providing treatment for persons with developmental delay. J Can Dent Assoc. 2008; 74:353-7. 
31. Al-Malik MI, Al-Sarheed MA. Comprehensive dental care of pediatric patients treated under general anesthesia in a hospital setting in Saudi Arabia. J Contemp Dent Pract. 2006; 7:79-88.

32. De Nova García MJ, Gallardo López NE, Martín Sanjuán C, Mourelle Martínez MR, Alonso García Y, Carracedo Cabaleiro E. Criteria for selecting children with special needs for dental treatment under general anaesthesia. Med Oral Patol Oral Cir Bucal. 2007; 12:E496-503.

33. Brown A. Caries prevalence and treatment needs of healthy and medically compromised children at a tertiary care institution in Saudi Arabia. East Mediterr Health J. 2009; $15: 378-86$.

34. Solanki N, Kumar A, Awasthi N, Kundu A, Mathur S, Bidhumadhav S. Assessment of Oral Status in Pediatric Patients with Special Health Care Needs receiving Dental Rehabilitation Procedures under General Anesthesia: A
Retrospective Analysis. J Contemp Dent Pract. 2016; 17:476-9.

35. Al-Maweri SA, Zimmer S. Oral Health Survey of 6-14-YearOld Children with Disabilities Attending Special Schools Yemen. J Clin Pediatr Dent. 2015; 39:272-6.

36. Harrison MG, Roberts GJ. Comprehensive dental treatment of healthy and chronically sick children under intubation general anesthesia during a 5-year period. Br Dent J. 1998; 184:503-7.

37. Al-Eheideb AA, Herman NG. Outcomes of dental procedures performed on children under general anesthesia. J Clin Pediatr Dent. 2003; 27:181-3.

38. Chen YP, Hsieh CY, Hsu WT, Wu FY, Shih WY. A 10 year trend of dental treatments under general anesthesia of children in Taipei Veterans General Hospital. J Chin Med Assoc. 2017; 80:262-8 